\title{
Analysis of physical activity level, the body mass index and skill in global motor teens
}

Deborah Cristina Gonçalves Luiz Fernani ${ }^{1,2}$, Maria Tereza Artero Prado ${ }^{1,2}$, Thais Massetti ${ }^{3}$, Talita Dias da Silva ${ }^{4}$, Lilian Del Ciello de Menezes $^{3}$ and Carlos Bandeira de Mello Monteiro ${ }^{3}$

${ }^{1}$ University of West Paulista, Presidente Prudente, SP, Brazil

${ }^{2}$ Department Health Sciences, the Faculty of Medicine of ABC, Santo André, SP, Brazil

${ }^{3}$ Post-graduate Program in Rehabilitation Sciences - Faculty of Medicine - University of São Paulo, São Paulo, SP, Brazil

${ }^{4}$ Post-graduate Program in Cardiology - Federal University of São Paulo - Paulista School of Medicine - São Paulo, SP, Brazil

\begin{abstract}
Introduction: Adolescence is the stage between childhood and adulthood, marked by a process of growth and biopsychosocial development, which adopted habits and behaviors tend to stabilize in adult.

Objective: To analyze the level of physical activity, body mass index and the motor age teens in school.

Method: Data were collected using the International Physical Activity Questionnaire, body mass index for age range of the Center for Disease Control and Prevention, and gross motor function tests based Development Motor Scale.

Results: Physical activity analysis showed that there was no physical inactivity due to physical education, but $44 \%$ was classified as insufficiently active, and $24 \%$ very active; BMI for age rated normal for $64 \%$, with $32 \%$ of obese; $92 \%$ of the sample was within the normal range of motor age, even with $11: 16$ months of delay in gross motor age compared to chronological age.
\end{abstract}

Conclusion: Each tool has been used independently, without establishing a relationship between the level of activity, BMI and motor age. Should join health professionals and family members to detect deviations growth and help in the development, intervening in the present and future life of the population.

\section{Introduction}

Adolescence is characterised by various biological, social and behavioural changes that significantly affect health habits, including social, family and cultural [1]. According to the World Health Organization (WHO) adolescence is the stage of life between childhood and adulthood, marked by a complex process of growth and biopsychosocial development that is present in people between 10 and 19 years of age. However, in Brazil, the Statute of Children and Adolescents uses the age range 12 to 18 to define the stage of adolescence.

During the motor development process there is a series of physical and mechanical changes [2], where gravitational mechanical forces (impact) and muscle contractions inherent to physical and sporting activity contribute to a healthy development of the skeletal system, providing greater bone mineral density without influencing longitudinal growth [3]. According to Dartagnan \& Grondin (2002) and Parmenter \& Wardle $(2000)[4,5]$, the acquisition and maintenance of healthy habits, such as proper nutrition and physical activity, are directly linked to improving quality of life and health, contributing to a reduction in various diseases.

There is evidence in the literature showing that habits and healthrelated behaviours adopted during childhood and adolescence tend to stabilise in adulthood [6]. Thus, stimulating physical activity at a young age should be a priority in public health, since engaging in daily physical activity has a significant role in health promotion and the prevention of hypokinetic diseases $[7,8]$.
According to Troiano et al. (2008) [9], less than 8\% of adolescents and $5 \%$ of American young adults follow the recommendations of a healthy diet and regular physical activity. A survey developed by the WHO (2010) points out that two thirds of adolescents under the age of 15 do not meet the recommendations for physical activity, i.e., at least 150 minutes per week of moderate physical activity or 75 minutes a week of vigorous physical activity with sessions of at least 10 minutes' duration without determining weekly frequency.

Physical activity is considered an important indicator of health, therefore, from an epidemiological point of view, it is essential to identify the amount of physical activity that a population performs at a given time, in order to establish the need to implement promotional strategies $[10,11]$.

Despite the recognised importance of physical activity for health and well-being, a large proportion of adolescents do not achieve

Correspondence to: Thais Massetti, Post-graduate Program in Rehabilitation Sciences - Faculty of Medicine - University of São Paulo, São Paulo, SP, Brazil Endereço. Rua Cipotânea, 51 Cidade Universitária - São Paulo - SP, CEP: 05360 000, E-mail: thaismassetti@gmail.com

Key words: adolescent, sedentary lifestyle, physical activity, psychomotor performance

Received: November 21, 2017; Accepted: December 20, 2017; Published: December 23,2017 
satisfactory levels [12]. According to Souza \& Duarte (2005) [13], $62.1 \%$ of adolescents are inactive or insufficiently active, boys being physically more active than girls. Young people tend to reduce physical activity levels along with their advancement in school grades, and this decline is also evident when analysing the data for chronological age.

Because of this significant reduction in levels of physical activity, researchers in the United States found that schools would be the most appropriate place for implementation of public policies to promote physical activity in children and adolescents [13]. As Harris et al. (2009) [14] suggest, school-based interventions are theoretically attractive because of adherence to interventions by teachers. There are a number of advantages to the strategy of promoting physical activity in school, such as ensuring full attendance of students due to the school curriculum and further guidance on the importance of practice and explanations about the consequence of inactivity due to established risk factors for chronic diseases [15].

There is good evidence that physical activity interventions in school are effective in increasing the duration of physical activity, reducing blood cholesterol and time spent watching television [15]. However, according to Fromel et al. (2016) [16], extracurricular physical activity, such as leisure with family and/or friends or playing sports, is also critical to health and especially to the physical, mental and social development of young people.

According to Lammle et al. [17] physical activity has positive effects on children's development, which plays an important role in motor skills. Observing motor development in teenagers leads to the possibility of detecting inadequate progress, allowing the development of interventions to reverse this situation. Therefore, this study is justified due to the current lifestyle of adolescents, as they are increasingly inactive and may not have motor development typical for their age group, as well as possible changes in the rates of weight and height. This study aims to analyse the level of physical activity, body mass index (BMI) by age, and motor age of teenagers, accomplished during school hours.

\section{Method}

All adolescents of 10 and 11 years old at a public school in the municipality of Presidente Prudente in Sao Paulo were recruited for this study. Effective participation in all stages of the study was carried out by 25 adolescents of both sexes, nine boys and 16 girls, with a mean chronological age of 133.1 months. Adolescents with any medical condition were excluded. The data collection started after approval of the research by the Ethics and Research Committee of Unoeste, and all parents and/or guardians signed the Informed Consent Form, CAEE Number: 411.

For the collection of data we used the International Physical Activity Questionnaire (IPAQ) [18], the BMI for age scale of the Centre for Disease Control and Prevention (CDC), and the global motor skills (GM) tests based on the Motor Development Scale (MDS) [19].

The level of physical activity of volunteers was evaluated by means of the IPAQ [18] and the Baecke Habitual Physical Activity Questionnaire [20].

The IPAQ is composed of questions that assess physical activity in an average week, which is subdivided into activity as a means of transport, activity at work, exercise and sport. According to the classification of the level of physical activity by IPAQ, individuals fall into:
- Sedentary - does not perform any physical activity for at least 10 continuous minutes during the week.

- Insufficiently active - individuals who practice physical activities for at least 10 minutes, but insufficiently to classify them as active.

- Active - individuals who do vigorous physical activity $\geq$ three days per week and $\geq 20$ minutes per session, moderate physical activity or walking $\geq$ five days per week and $\geq 30$ minutes per session, or any activity added up to reach $\geq$ five days per week and $\geq 150$ minutes per session.

- Very active - vigorous activity $\geq$ five days per week and $\geq 30$ minutes per session, vigorous activity $\geq$ three days per week and $\geq 20$ minutes per session, and more moderate activity $\geq$ five days per week and $\geq$ 30 minutes per session [21].

The Baecke Habitual Physical Activity Questionnaire is a reminder tool for the last 12 months, consisting of 16 questions which cover three scores of habitual physical activity, i.e., occupational physical activity, physical exercise in leisure, and recreational physical activity and locomotion [22].

The collection of height and weight data was held followed by the analysis of these through the BMI by age scale of the CDC.

Then there was the assessment of the GM through the MDS, either according to the chronological age of the adolescent, or via the adolescent performing the tasks starting from their chronological age until they cannot complete the task and then the General Motor Age (GMA) is defined based on the results.

When failure occurs in the task corresponding to chronological age, the previous task It is performed and, if successful, the child performs next task, if it fails again, performs previous. You can observe a suppleness with regarding successes and failures, however, since that a test can not be overcome is not offered the opportunity to conduct further testing there was the failure. In this context, children were able to perform the following tasks that failed, this result would not be considered [23]. The results were calculated for the highest score described in months. The development of motor quotient (QM = MG/ IC x 100) was ranked as much higher, superior, normal high, average normal, low normal, bottom, or much lower. Adolescents who had impairments were instructed to seek health services which have the power to prescribe appropriate treatment.

The descriptive statistical method was used for the analysis of the results, which were presented as mean values.

\section{Results}

During the IPAQ a precise explanation was given to adolescents so they could properly answer the questions. The data are shown in Figure 1 . The level of physical activity assessed by the IPAQ showed no inactivity due to physical education, but $44 \%$ of the sample were ranked as insufficiently active, and only $24 \%$ as very active.

The analysis score of occupational physical activities in the application of the Baecke questionnaire was excluded because no subject of the sample was working. The teenagers evaluated by the Baecke questionnaire obtained a mean score of $6.18 \pm 0.86$. There is an additional classification to this finding to analyse the spectrum of scores, with a minimum of 3.45 to a maximum of 12.27 . This suggests that if the sample in the last 12 months performed little physical activity, scoring below average would be 7.86 . 


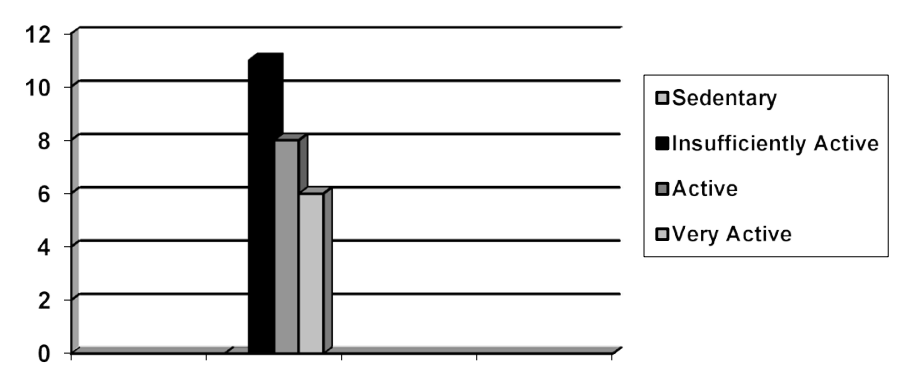

Figure 1. Sample classification according to IPAQ

The results obtained with respect to the mean BMI/age were 19.18 $\mathrm{kg} / \mathrm{m} 2$, this figure being classified as normal or eutrophic. The other values can be seen in Figure 2. The BMI for age rated $64 \%$ of adolescents as normal and $32 \%$ as obese.

When comparing the average GMA with the mean chronological age there was a slight advantage that can be seen in Figure 3. The motor age is presented within normal range in $92 \%$ of the sample, even with 11.16 months of delay in gross motor age in relation to chronological age. To sort the MDS for GM need to realise Quotient General Motor with an average of 91.53 , this means average normal. We can observe the overall rating of the GM according to MDS in Figure 4.

\section{Discussion}

This study showed that we can independently analyse the index of physical activity, body weight and motor function in adolescents through different tests. For the analysis of physical activity during the period of a week, the IPAQ [18] found that there was no physical inactivity in adolescents due to practical exercises during the school period. It is known that school physical education is a favourable environment to promote behaviour change [24], because it is believed that it contributes to an increase in physical activity $[25,26]$

It is important to note that school physical education does not determine the optimal level of activity, it contributes only a small portion to the desired degree of physical activity. This because it is usually carried out at low intensity and low frequency during the school schedule [27]. This is observed in a study by Rivera et al. [28], where $93.5 \%$ of the assessed young people did not exercise at moderate to intense levels throughout the week. These data corroborate the results found in this study where $44 \%$ of students were classified as insufficiently active, even when performing regular activities at school.

Following this reasoning, physical education teachers should encourage and motivate students to conduct activities during leisure time [29-31]. School breaks and the practice of extracurricular sports present opportunities to engage students in physical activities [32]. To quantify leisure activities and time for individual travel, the Baecke questionnaire [32] can be used, where the selected statistical data in a study Dartagnan et al. [33] indicate that it can be defined as a valid instrument directed to follow the usual practice of physical activity, particularly among older adolescents. Thus, according to the results found in the last 12 months, the participants performed physical activity below average during their daily activities.

One of the factors contributing to the inactivity of young people is the reduction in the physical effort of travelling to school and hobbies, and an increase in time in passive activities, such as electronic games and computer games or television [34] In a longitudinal study that followed 1,000 young people from five to 15 years old and then until the age of 26 [35], it was demonstrated that the higher the number of hours watching television, the higher the BMI, the cholesterol level, and the smoking prevalence, and the worse the physical fitness in childhood and adolescence, and these variables remained in adulthood.

According to Silva et al. [36], good relationships with colleagues during the school year also negatively influences adolescents to present sedentary behaviours, due to the large amount of time needed for static and online activities. Areas where the activity is carried out (at home, at work, on transport, and leisure time) and the age, sex, ethnic origin, and socioeconomic status also directly influence the level and frequency of activities [37]. These results confirm the importance of the social environment to active lifestyles [38], and suggest that a specific approach to the context should be taken to develop effective interventions [36].

Studies involving anthropometric assessment, especially body mass, have been the most widely used form for the assessment of nutritional status and regulation of growth in children and adolescents, and cases of malnutrition or obesity can be detected early through this method [39]. The increasing prevalence of being overweight and obese at increasingly early ages has aroused the concern of researchers and health professionals, because of health problems, such as hypertension, heart disease, diabetes, and being hyperlipidemic $[40,41]$

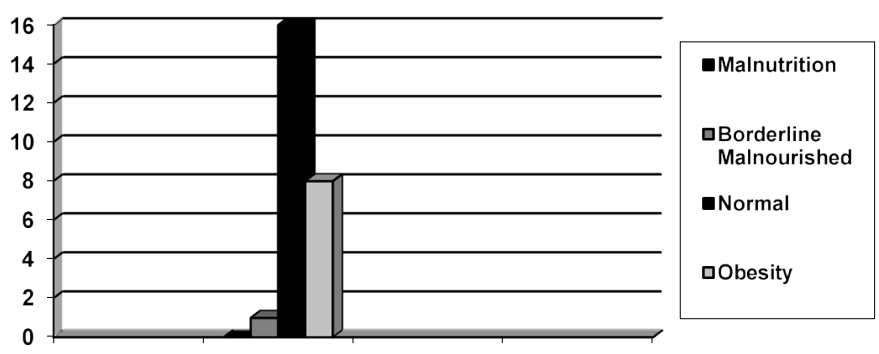

Figure 2. Sample classification according to BMI/Age

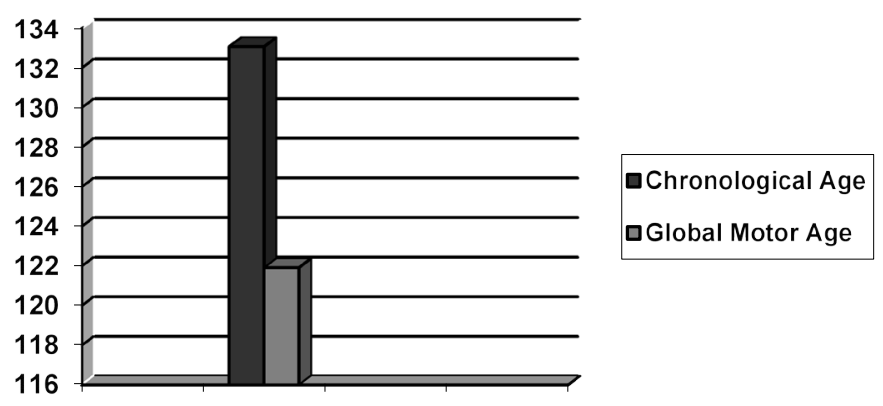

Figure 3. Comparison of the performance of the global motor age according to MDS and chronological age.

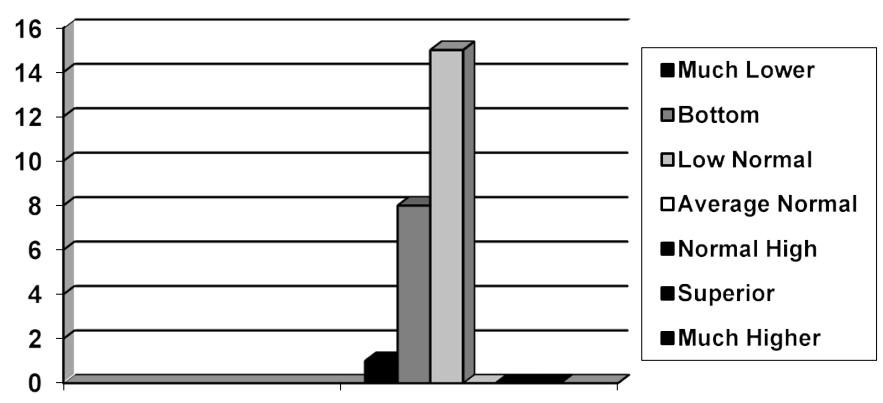

Figure 4. GM Classification according to MDS 
The ability to measure or quantify body fat reserves is key to preventing and treating obesity-related diseases [42]. The degree of obesity has been defined in most epidemiological studies by BMI [43], establishing itself as a reference for the classification of weight status to normal, overweight and obese [44].

In the last three decades, the prevalence of being overweight among young people has increased significantly in several countries, including Brazil [45]. According to a study Sulemana et al. [46], girls who were overweight and obese had, respectively, $10 \%$ and $6 \%$ less physical activity compared to those of normal weight. This association was not found in our study, where $64 \%$ of adolescents had BMI classified as eutrophic or normal even with activity below the recommended average. However, eight teenagers had obesity which could negatively impact future life due to degenerative, cardiovascular and musculoskeletal diseases from the excess weight. According to a longitudinal study of more than 2,500 participants, $77 \%$ of children who were overweight became obese adults, as classified by BMI [47]. These data reinforce the need to increase physical activity by teenagers.

The evidence suggests that the acquisition of motor skills in early childhood may be an important prerequisite for the participation of children in activities and engagement in physical activity later in life [48] thereby reducing the risk of developing cardiovascular diseases [49]. Among the predisposing factors are vascular changes, early family history, obesity, sedentary lifestyle, ethnicity, and psychosocial factors [50]. In this study, we only assessed obesity and physical activity, where both pose risks for these individuals.

Another factor analysed in the study was overall motor skills through the MDS, which is generally conducted in order to assess, analyse and study the development of children at different developmental stages [19]. Our results showed that the global motor age of the adolescents showed a relatively late development in relation to chronological age but was classified as normal average.

According to Caetano et al. [51], the process of development of each traction component has both dynamic aspects and features of non-linearity. These variations among children of the same age are evidenced by the differences in the speed of the biological maturation process, in which young people with early development outperform others [52]. In a study by Bojikian et al., [53] of motor performance tests, significant differences were not found in most comparisons between groups of different maturational stages within the same age group, indicating that the different maturational stages were not decisive for better performance, especially in indicators testing agility, abdominal strength and flexibility.

Physical activity in childhood and adolescence associated with physical growth, sexual maturation, and behavioural development are frequent discussions in the context of the future health of the individual. This scenario shows that the evidence is strong for the beneficial effects of physical activity for musculoskeletal health, cardiovascular health, and the presence of adiposity in young overweight people [8]. Thus, an increased level in physical activity of moderate to vigorous intensity in adolescence is promoting health and a strategy for disease prevention, where sedentary young people should progress to the recommended level of physical activity gradually.

\section{Conclusion}

In this study each assessment tool proved to be independent and it was not possible to establish a relationship between the level of physical activity, BMI and the motor age, except that adolescents classified as normal in the CDC scale tended to have normal rating for the MDS, unrelated to the level of physical activity. Therefore, we should unite education and health professionals, such as physiotherapists, with families to detect growth deviations and assist the most rapid development possible, contributing to a more appropriate interaction with teenagers, positively intervening in the present life and their future.

\section{References}

1. Moreira RM, Boery EN, Oliveira DCd (2015) Social representations of adolescents on quality of life: structurally-based study. Ciência Saúde Coletiva 20: 49-56. [Crossref]

2. Gallahue DL (2002) Desenvolvimento Motor E Aou1 sigao da Competencia Motora Na Educaqao De Infancia.

3. Ortega FB1, Ruiz JR, Castillo MJ, Sjöström M (2008) Physical fitness in childhood and adolescence: a powerful marker of health. Int J Obes (Lond) 32: 1-11. [Crossref]

4. Parmenter K, Wardle J (2000) Evaluation and design of nutrition knowledge measures. Journal of Nutrition Education 32: 269-277.

5. Guedes DP, Grondin LMV (2002) Perception of healthy habits by adolescents: association with alimentare indicators, practice of physical activity and control of body weight. Revista brasileira de Ciências do Esporte. 24: 1-10.

6. Lobstein T, Baur L, Uauy R (2004) IASO International Obesity TaskForce Obesity in children and young people: a crisis in public health. Obes Rev 5: 4-104. [Crossref]

7. Petroski EL, Pelegrini A (2009) Association between the parents' lifestyle and the body composition of the adolescent children. Rev Paul Pediatr 27: 48-52.

8. Strong WB, Malina RM, Blimkie CJ, Daniels SR, Dishman RK, et al. (2005) Evidence based physical activity for school-age youth. J Pediatr 146: 732-737. [Crossref]

9. Troiano RP, Berrigan D, Dodd KW, Mâsse LC, Tilert T, et al. (2008) Physical activity in the United States measured by accelerometer. Med Sci Sports Exerc 40: 181-188. [Crossref]

10. Bauman A, Phongsavan P, Schoeppe S, Owen N (2006) Physical activity measurement-a primer for health promotion. Promotion education 13: 92-103. [Crossref]

11. Pedersen B, Saltin B (2015) Exercise as medicine-evidence for prescribing exercise as therapy in 26 different chronic diseases. Scandinavian journal of medicine \& science in sports 25: 1-72. [Crossref]

12. Farias J (2008) Association between prevalence of physical inactivity and indicators of socio-economic status in adolescents. Revista Brasileira de Medicina do Esporte 14: $109-114$.

13. Souza G, Duarte M (2005) Stages of behavioral change related to physical activity in adolescents. Rev. bras. med. Esporte 11:104-108.

14. Harris KC, Kuramoto LK, Schulzer M, Retallack JE (2009) Effect of school-based physical activity interventions on body mass index in children: a meta-analysis. Canadian Medical Association Journal 180:719-726. [Crossref]

15. Dobbins M, DeCorby K, Robeson P, Husson H, Tirilis D (2009) School-based physical activity programs for promoting physical activity and fitness in children and adolescents aged 6-18. Cochrane Database Syst Rev 1: 1-10. [Crossref]

16. Fromel K, Kudlacek M, Groffik D, Chmelik F, Jakubec L (2016) Differences in the intensity of physical activity during school days and weekends in Polish and Czech boys and girls. Ann Agric Environ Med 23: 357-360. [Crossref]

17. Lammle C, Kobel S, Wartha O, Wirt T, Steinacker JM (2016) Intervention effects of a school-based health promotion program on children's motor skills. Z Gesundh Wiss. 24: 185-192.

18. Matsudo S, Araújo T, Marsudo V, Andrade D, Andrade E, et al. (2001) International Physical Activity Questionnaire (IPAQ): a study of validity and reproducibility in Brazil. Rev 6: 5-18.

19. Neto R, Dos Santos APM, Xavier RFC, Amaro KN (2010) The Importance of motor evaluation in schoolchildren: analysis of the reliability of the Motor Development Scale. Rev Bras Cineantropom Desempenho Hum 12: 422-427.

20. Baecke JA, Burema J, Frijters J (1982) A short questionnaire for the measurement of habitual physical activity in epidemiological studies. The American journal of clinical nutrition 36: 936-942. [Crossref]

21. Booth ML, Ainsworth BE, Pratt M, et al. (2003) International physical activity questionnaire: 12-country reliability and validity. Med sci sports Exerc 195: 35081381. [Crossref] 
22. Florindo AA, Latorre M (2003) Validation and reliability of the Baecke questionnaire for the evaluation of habitual physical activity in adult men. Revista Brasileira de Medicina do Esporte 9:129-135.

23. Silveira CRA, Menuchi M, Simões CSA, Caetano MJD, Gobbi LTB (2006) Validity of construction in equilibrium tests: chronological ordering in the presentation of tasks. Rev Bras Cineantropom Desempenho Hum 8: 66-72.

24. Atkin AJ, Gorely T, Biddle S, Marshall SJ, Cameron N (2008) Critical hours: physical activity and sedentary behavior of adolescents after school. Pediatr Exerc Sci 20: 446456. [Crossref]

25. Barros MV, Nahas MV, Hallal PC, Farias Júnior JC, Florindo AA, et al. (2009) Effectiveness of a school-based intervention on physical activity for high school students in Brazil: the Saude na Boa project. J Phys Act Health 6: 163-169. [Crossref]

26. Gordon LP, McMurray RG, Popkin BM (2000) Determinants of adolescent physical activity and inactivity patterns. Pediatrics 105: e83-e83. [Crossref]

27. Silva KS, Nahas MV, Peres KG, Lopes AD (2009) Factors associated with physical activity, sedentary behavior, and participation in physical education among high school students in Santa Catarina State, Brazil. Cadernos de Saúde Pública 25: 2187-2200. [Crossref]

28. Rivera IR, Silva MAMd, Silva RD, Oliveira BAV, Carvalho ACC (2010) Physical inactivity, TV-watching hours and body composition in children and adolescents. Arquivos brasileiros de cardiologia 95: 159-165. [Crossref]

29. Zhang T (2009) Relations among school students' self-determined motivation, perceived enjoyment, effort, and physical activity behaviors. Perceptual and motor skills 109: 783-790. [Crossref]

30. Bagøien TE, Halvari H, Nesheim H (2010) Self-determined motivation in physical education and its links to motivation for leisure-time physical activity, physical activity, and well-being in general. Perceptual and Motor skills 111: 407-432. [Crossref]

31. Jaakkola T, Washington T, Yli-Piipari S (2012) The association between motivation in school physical education and self-reported physical activity during Finnish junior high school: A self-determination theory approach. European Physical Education Review.

32. Fox KR, Cooper A, McKenna J (2004) The school and the promotion of children's health-enhancing physical activity: perspectives from the United Kingdom. Journal of Teaching in Physical Education 23: 338-358.

33. Guedes DP, Lopes CC, Guedes JE, Stanganelli LC (2006) Reproducibility and validity of the Baecke questionnaire for assessment of habitual physical activity in adolescents. Revista Portuguesa de Ciências do Desporto 6: 265-274.

34. Vasconcelos MA, Maia J (2001) Physical activity of children and young people-will there be a decline? Cross-sectional study in subjects of both sexes from 10 to 19 years of age. Revista Portuguesa de Ciências do Desporto 1: 44-52.

35. Hancox RJ, Milne BJ, Poulton R (2004) Association between child and adolescent television viewing and adult health: a longitudinal birth cohort study. The Lancet 364 : 257-262. [Crossref]

36. Silva DR, Fernandes RA, Ohara D (2016) Correlates of sports practice, occupational and leisure-time physical activity in Brazilian adolescents. American Journal of Human Biology 28: 112-117. [Crossref]
37. Bauman AE, Reis RS, Sallis JF (2012) Correlates of physical activity: why are some people physically active and others not? The lancet 380: 258-271

38. Fermino RC, Rech CR, Hino AAF, Rodriguez CR, Reis RS (2010) Physical activity and associated factors in high-school adolescents in Southern Brazil. Revista de Saúde Pública 44: 986-995. [Crossref]

39. Organization WH (2002) How much physical activity needed to improve and maintain health.

40. Johnson WD, Kroon JJ, Greenway FL, Bouchard C, Ryan D, et al. (2009) Prevalence of risk factors for metabolic syndrome in adolescents: National Health and Nutrition Examination Survey (NHANES), 2001-2006. Archives of Pediatrics \& Adolescent Medicine 163: 371-377. [Crossref]

41. Lee YS (2009) Consequences of childhood obesity. Ann Acad Med Singapore 38: 7577. [Crossref]

42. Peltz G, Aguirre MT, Sanderson M, Fadden MK (2010) The role of fat mass index in determining obesity. American Journal of Human Biology 22: 639-647. [Crossref]

43. Schutz Y, Kyle U, Pichard C (2002) Fat-free mass index and fat mass index percentiles in Caucasians aged 18-98 y. International Journal of Obesity \& Related Metabolic Disorders 26: 1-10. [Crossref]

44. Katzmarzyk PT, Srinivasan SR, Chen W, Malina RM, Bouchard C, et al. (2004) Body mass index, waist circumference, and clustering of cardiovascular disease risk factors in a biracial sample of children and adolescents. Pediatrics. 114: e198-e205.

45. Wang Y, Monteiro C, Popkin BM (2002) Trends of obesity and underweight in older children and adolescents in the United States, Brazil, China, and Russia. The American journal of clinical nutrition 75: 971-977.

46. Sulemana H, Smolensky MH, Lai D (2006) Relationship between physical activity and body mass index in adolescents. Medicine and science in sports and exercise 38 : $1182-1186$.

47. Freedman DS1, Khan LK, Dietz WH, Srinivasan SR, Berenson GS (2001) Relationship of childhood obesity to coronary heart disease risk factors in adulthood: the Bogalusa Heart Study. Pediatrics 108: 712-718. [Crossref]

48. Loprinzi PD, Cardinal BJ, Loprinzi KL, Lee H (2012) Benefits and environmenta determinants of physical activity in children and adolescents. Obesity Facts 5: 597-610.

49. Druce Axley J, Werk LN (2016) Relationship Between Abdominal Adiposity and Exercise Tolerance in Children with Obesity. Pediatr Phys Ther.

50. Power C, Pinto Pereira SM, Law C, Ki M (2014) Obesity and risk factors for cardiovascular disease and type 2 diabetes: investigating the role of physical activity and sedentary behaviour in mid-life in the 1958 British cohort. Atherosclerosis 233: 363-369.

51. Caetano MJD, Silveira CRA, Gobbi LTB (2005) Motor development of preschoolers within 13 months. Rev Bras Cineantropom Desempenho Hum 7: 5-13.

52. Philippaerts RM, Vaeyens R, Janssens M (2006) The relationship between peak heigh velocity and physical performance in youth soccer players. Journal of sports sciences. 24: $221-230$.

53. Bojikian LP, Teixeira CP, Böhme MTS (2005) Relationship between growth, motor performance, biological maturation and chronological age in young males. Revista Brasileira de Educação Física e Esporte 19: 153-162.

Copyright: C2017 Fernani DCGL. This is an open-access article distributed under the terms of the Creative Commons Attribution License, which permits unrestricted use, distribution, and reproduction in any medium, provided the original author and source are credited. 